\title{
Comprehensive Model of Oxygen Steelmaking Part 3: Decarburization in Impact Zone
}

\author{
Neslihan DOGAN, Geoffrey Alan BROOKS and Muhammad Akbar RHAMDHANI \\ Faculty of Engineering and Industrial Science, Swinburne University of Technology, Hawthorn, VIC 3122 Australia. \\ Email: doganeslihan@gmail.com
}

(Received on February 8, 2011; accepted on April 20, 2011)

\begin{abstract}
The development of a global model for oxygen steelmaking and its validation against industrial data has been reported in Part 1 of this paper. Part 2 of this paper explained the model development of decarburization reaction of emulsified droplets and discussed the effects of bloating behaviour of metal droplets on the overall kinetics of the process. Part 3 of this paper focussed on the development of one sub-model on the decarburization reaction in the impact zone and critically evaluates the important process variables affecting the decarburization kinetics. Decarburization rates in the impact zone were calculated using the semi-empirical relationships developed from experimental results. Based on previous experimental studies, both diffusion through the gas phase and surface control were considered in the rate calculations. The model was validated against experimental data from Belton and Sain, and against plant data from Cicutti et al. The model developed was consistent with the experimental and plant data, and provided a reasonable basis for predicting the decarburization of iron in the impact region of oxygen steelmaking. The model predicted that the decarburization rate is sensitive to the partial pressure of carbon dioxide and oxygen in the impact zone. As the partial pressure of oxygen decreased from 26.4 to 16.2 $\mathrm{kPa}$, the model predicted that that the reaction rate of decarburization via oxygen decreased from 202 to $134 \mathrm{~kg} / \mathrm{min}$. The model predicted that approx. $40 \%$ of decarburization takes place in the impact zone during the main blow.
\end{abstract}

KEY WORDS: impact area; gas diffusion; sulphur; decarburization rate; oxygen steelmaking.

\section{Introduction}

The reactions between metal bath and oxidizing gasses are of particular interest, as a significant proportion of carbon removal in oxygen steelmaking occurs in the impact zone in the reactor. ${ }^{1-3)}$ Unfortunately, distinguishing between decarburization from the emulsion and impact zones is very difficult from the analysis of plant data, where only the overall rate of carbon removal is measured. Also, duplicating the conditions of oxygen steelmaking experimentally is challenging. We have attempted to address this issue by developing models for both the emulsion zone (Part $2^{4)}$ ) and the impact zone (current paper), combining them together into a global model and comparing them to the best plant data available (Part $1^{5)}$ of this series of papers).

It is known, as oxygen from a top blown lance reaches the surface of the liquid bath, it reacts with carbon dissolved in the metal at the impact zone and forms a mixture of $\mathrm{CO}$ and $\mathrm{CO}_{2}$ gases. Subsequently, dissolved carbon also reacts with $\mathrm{CO}_{2}$ simultaneously at this region. The following equations can be used to represent the decarburization reactions at the impact area; ${ }^{6}$

$$
\begin{aligned}
& {[\mathrm{C}]+\mathrm{CO}_{2(g)}=2 \mathrm{CO}_{(g)}} \\
& {[\mathrm{C}]+1 / 2 \mathrm{O}_{2(g)}=\mathrm{CO}_{(g}}
\end{aligned}
$$

The possible reaction mechanisms for above reactions are given below;

(i) mass transfer of oxygen in the gas phase

(ii) mass transfer of carbon monoxide in the gas phase

(iii) mass transfer of carbon dioxide in the gas phase

(iv) mass transfer of carbon through metal phase

(v) chemical reaction between carbon and oxygen at the interface

Steps (i),(ii) and (vi) apply to decarburization reaction with $\mathrm{O}_{2}$ whereas (ii), (iv) and (vi) apply to decarburization reaction with $\mathrm{CO}_{2}$. It has been postulated that the mass transfer of carbon can be neglected at high carbon concentrations (above critical carbon content). ${ }^{1,6-11)}$ The adsorption of oxygen can also be neglected since oxygen has been present already in the liquid iron.

There have been numerous studies ${ }^{1,3,7-35)}$ on the mechanism and kinetics of decarburization of $\mathrm{Fe}-\mathrm{C}$ melts with oxidizing gasses using levitation and crucible techniques. The conclusion from the previous studies is in general agreement, i.e. gaseous diffusion controls the decarburization rate down to the critical level of carbon, where carbon diffusion in liquid phase becomes rate-limiting step. However, some investigators have suggested that sulphur has a determining effect on the reaction rate and chemical reaction at the interface also controls the reaction rate. ${ }^{30)}$

Previous experimental studies, both in laboratory and 
industrial scales, have improved the fundamental understanding of decarburization reactions via gases during the blowing process. ${ }^{1,3,7-35)}$ Despite this, there is only limited industrial data $^{36}$ that consider carbon removal rates via direct oxidation at the impact zone due to the complexity of the process. This study is an attempt to use the theoretical findings from the experimental studies to the full-scale operating conditions.

\section{Model Development}

\subsection{Rate-Determining Step}

In this study, it has been considered that decarburisation reactions in the impact zone varying over a large range of temperature and fluid flow conditions, with constant concentration of sulphur. In the case of decarburization reaction via $\mathrm{CO}-\mathrm{CO}_{2}$, Nomura and Mori ${ }^{17)}$ and Fruehan and Martonik $^{20)}$ proposed that the effect of sulphur (sulphur concentration below 0.3 mass\%) is relatively small on the reaction rate in $\mathrm{CO}-\mathrm{CO}_{2}$ gas mixture at high carbon concentrations. Goto et al. $^{34)}$ reported that sulphur has no significant effect on the reaction kinetics. Later, Sain and Belton ${ }^{7)}$ and Mannion and Fruehan ${ }^{1)}$ studied the decarburization kinetics under high gas flow rates and found that $\mathrm{CO}_{2}$ dissociation on the surface controls the reaction rate. Lee and $\mathrm{Rao}^{8,9)}$ proposed that the surface active elements, the gas flow rate, partial pressure of oxygen and gas composition have an influence on the decarburization rate. However, the rate of decarburization is markedly controlled by the composition of gas since it determines the amount of oxygen transferred to the system.

A model based on a mixed control kinetics including gas phase mass transfer and chemical kinetics from the study by Sain and Belton ${ }^{7,30)}$ was used since it has been established that sulphur has a retarding effect on the kinetics of decarburization reaction ${ }^{1,26,30,37)}$ and this effect was included in our model to investigate the reaction rates of decarburization under various operational conditions. The rate equation for decarburization reaction via $\mathrm{CO}_{2}$ can be written by; ${ }^{7,30}$ )

$$
\frac{-d W_{C}}{d t}=100 m w_{C} A k_{a} P_{C O_{2}}^{b}
$$

where

$$
k_{a}=\frac{1}{R T_{f} / k_{g}+1 / k_{t}}
$$

Here $k_{g}, k_{t}$ and $k_{a}$ are the gas phase mass transfer coefficient, chemical rate constant and apparent rate constant, respectively. $P_{\mathrm{CO}_{2}}^{b}$ is the partial pressure of $\mathrm{CO}_{2}$ in the gas mixture, $R$ is the gas constant, $T_{f}$ is the average gas film temperature, $A$ is the surface area and $m w_{C}$ is molecular weight of carbon.

In this study, it was assumed that the rate of decarburization via oxygen was controlled by mass transfer in the gas phase since it has been established that gas diffusion has the predominant effect on the reaction kinetics and surface active elements play no important role on the reaction mechanism. $^{10,11,16,21)}$ The rate equation can be written using; ${ }^{10,16)}$

$$
\frac{-d W_{C}}{d t}=200 m w_{C} A k_{g} \ln \left(1+P_{O_{2}}^{b}\right)
$$

Equations (3) and (5) were applied to determine the reaction rates during the blowing period in which the carbon content was high. Below a critical value, carbon diffusion in the liquid phase was considered to control reaction rates of decarburization. The rate equation was represented in mass unit by the Eq. (6); ${ }^{7)}$

$$
\frac{d W_{C}}{d t}=k_{m} A \frac{\rho_{m}}{100}\left(\operatorname{mass} \% C_{b}-\operatorname{mass} \% C_{e q}\right)
$$

where $\rho_{m}$ is density of liquid iron and $k_{m}$ is mass transfer coefficient of carbon in liquid iron. The equilibrium carbon content, $C_{e q}$ was small and neglected in the calculations.

Most of the experimental studies focused on the decarburization reaction of $\mathrm{Fe}-\mathrm{C}$ melts or droplets and the effect of sulphur on the reaction mechanism was investigated. There are few studies ${ }^{12,23,24,27)}$ that consider the influences of other refining reactions on the decarburization kinetics. Robertson and Jenkins ${ }^{12)}$ observed the behaviour of levitated droplets containing $\mathrm{C}, \mathrm{Si}$ and $\mathrm{Al}$ with oxygen. They found that the silicate layers formed initially on $\mathrm{Fe}-\mathrm{C}-\mathrm{Si}$ droplets which retard the decarburization reaction. Similar behaviour was observed by Sun and Pehlke. ${ }^{24)}$ They studied the kinetics of simultaneous oxidation of carbon, silicon, manganese and sulphur in a liquid metal droplet by oxygen and/or carbon dioxide in nitrogen gas at 1873 to $1993 \mathrm{~K}$. They observed that there was a delay in silicon and manganese oxidation reactions at high temperatures and high carbon contents since the decarburization reaction consumed the most of the oxygen supplied to the system. In the case of low carbon content $(<0.4$ mass $\%)$, the simultaneous oxidation of manganese and silicon was observed in their experiments. The effects of other refining reaction was ignored in this study, it is difficult to relate the experimental results from droplets to the impact region of an oxygen steelmaking vessel and it is reasonable to assume that any silicate layer formed would quickly dissolve into the slag. Further experimental work is required to clarify the impact of other elements on decarburization in the impact region.

\subsection{Calculation of Rate Constants}

There are few studies ${ }^{7,38-42)}$ for impinging gas jets at metal surface. Based on the study of Rao and Trass, ${ }^{38)}$ Sain and Belton ${ }^{7)}$ suggested a mass transfer correlation for the case of an impinging jet onto a liquid surface.

$$
S h=0.026 \operatorname{Re}^{1.06} S c^{0.53}\left(\frac{z^{\prime}}{d_{t}}\right)^{-0.09}
$$

This correlation is valid for $\left(z^{\prime} / d_{t}\right) \leq 6.5,\left(x / d_{t}\right) \leq 4.5$, which is not the case in the industrial configuration. Lohe ${ }^{41)}$ also suggested mass transfer correlations for gas side mass transfer, which were given based on the range of Reynolds number;

$$
\begin{aligned}
& S h=1.41 \operatorname{Re}^{0.51} S c^{0.33}, \quad 2 \cdot 10^{2} \leq \operatorname{Re} \leq 3 \cdot 10^{4} \ldots \\
& S h=0.41 \operatorname{Re}^{0.75} S c^{0.53}, \quad 3 \cdot 10^{4} \leq \operatorname{Re} \leq 2 \cdot 10^{5} \ldots
\end{aligned}
$$

Here $S h=k_{m} r_{0} / D, R e=u r_{0} \rho / \mu$ and $S c=\mu /(\rho D) . d_{t}$ refers to nozzle throat diameter and $z^{\prime}$ denotes to the distance of the nozzle from the surface of the liquid. Interdiffusivity, viscosity and density of fluid (gas) at $T_{f}$ are $D, \mu$ and $\rho$, 
respectively. $S c$ varies between 0.1 and 2 for gases. ${ }^{43)}$ These correlations were used for the range of the Reynolds number applicable in this study. The velocity of the gas to be inserted into the Reynolds number was designated as the mean velocity of the gas. In this study, it was assumed to be equal to the impact velocity from the oxygen lance. The impact velocity was related with jet centreline velocity at the metal surface which can be obtained using: $:^{44,45)}$

$$
U_{G}=\eta U_{j}
$$

$\eta$ is a constant and its value is 0.44721 . The jet centreline velocity can be obtained by the equation for the dynamic impact pressure of the jet at the metal surface. ${ }^{6}$ )

Variable $r_{0}$ is the radius of inundated surface area. In this study, the variable $r_{0}$ was considered to be the radius of individual penetration area. There are few proposed correlations $^{46-50)}$ to calculate the diameter of the penetration area. The correlation developed by Koria and Lange ${ }^{50)}$ was used to estimate the diameter of the cavity since this study was based on an experimental study at steelmaking temperatures and the penetration correlations have been widely used by many researchers.

According to the Sain and Belton ${ }^{7,30)}$ and Nagasaka and Fruehan, ${ }^{51)}$ the rate constant of dissociative adsorption of $\mathrm{CO}_{2}$ for liquid $\gamma$-iron by $\mathrm{CO}-\mathrm{CO}_{2}$ was;

$$
k_{t}=\frac{k_{f}}{1+K_{s} \gamma_{s}(\text { mass } \% S)}+k_{r}
$$

where $k_{f}, k_{r}, K_{s}$ and $\gamma_{s}$ refer to chemical rate constant for pure iron, residual rate at high sulphur contents, adsorption coefficient of sulphur and activity coefficient of sulphur in liquid iron, respectively. In the study of Nagasaka et al., ${ }^{51)}$ the standard state for sulphur activity was taken as 1 mass $\%$ in carbon-saturated liquid iron that the activity coefficient was assumed to be equal to unity for carbon-saturated liquid iron. Rate constants $k_{f}, k_{r}$ and adsorption coefficient, $K_{s}$ can be calculated as a function of temperature using, ${ }^{30,51)}$

$$
\begin{aligned}
& \log k_{f}=-\frac{5080}{T}-0.21 \\
& \log k_{r}=-\frac{5600}{T}-1.75 \\
& \log K_{s}=-\frac{3600}{T}+0.57
\end{aligned}
$$

In the case of mass transfer in the metal phase, mass transfer coefficient was related to the stirring intensity in the metal bath. Several researchers ${ }^{52-55)}$ proposed a correlation between mass transfer coefficient to gas flow rate for gas stirred liquid-liquid systems. Accordingly, the mass transfer coefficient can be found using;,6,56)

$$
k_{m}=\beta\left(\frac{D_{C} \cdot F_{G}}{A}\right)^{1 / 2}
$$

where $\beta$ is constant and equal to $500 \mathrm{~m}^{-0.5} \cdot{ }^{56)} F_{G}$ is the volumetric gas flow rate $\left(\mathrm{m}^{3} / \mathrm{s}\right)$ and it was assumed that inert gas blowing from the bottom of the furnace influences the mixing in the bath. $D_{c}$ is the diffusion coefficient of carbon. The relationship between diffusivity in liquids and temper- ature and viscosity of liquid by the Stokes-Einstein and Eyring equations was used to calculate the diffusivities of carbon in liquid iron for various temperatures.

\subsection{Calculation of Partial Pressure}

Determination of partial pressure of oxidizing gasses such as $\mathrm{CO}_{2}$ and $\mathrm{O}_{2}$ is crucial since it governs the amount of gas delivered to the system in order to achieve the reactions at the impact zone. The partial pressure of the gases in the system varies as a function of reaction rates and gas composition. In this model, it was assumed that the amount of gas blown $\left(\mathrm{O}_{2}\right.$ and $\left.\mathrm{Ar}-\mathrm{N}_{2}\right)$ and $10 \%$ of the total amount of gas generated from the decarburization reaction were available in the impact zone for the given time interval. The gas generation by the decarburization reaction via emulsion was not included in the calculations of partial pressure of gasses in the impact zone. In this model, the total amount of gas available in the system was calculated by the summation of the gasses $\left(\mathrm{O}_{2}, \mathrm{CO}, \mathrm{CO}_{2}\right.$ and $\left.\mathrm{Ar}-\mathrm{N}_{2}\right)$ in unit of mol over time interval. The partial pressure of $\mathrm{CO}_{2}$ and $\mathrm{O}_{2}$ were calculated from the molar rates of $\mathrm{Ar}-\mathrm{N}_{2}\left(N_{A}\right), \mathrm{O}_{2}\left(N_{O_{2}}\right), \mathrm{CO}\left(N_{C O}\right)$ and $\mathrm{CO}_{2}\left(\mathrm{~N}_{\mathrm{CO}_{2}}\right)$ and the average pressure in the bath $(P)$ :

$$
\begin{gathered}
P_{\mathrm{CO}_{2}}=\left(\frac{N_{\mathrm{CO}_{2}}}{N_{\mathrm{CO}_{2}}+N_{\mathrm{CO}}+N_{\mathrm{A}}+N_{\mathrm{O}_{2}}}\right) \times P \ldots \ldots \ldots . . . \\
P_{\mathrm{O}_{2}}=\left(\frac{N_{\mathrm{O}_{2}}}{N_{\mathrm{CO}_{2}}+N_{\mathrm{CO}}+N_{\mathrm{A}}+N_{\mathrm{O}_{2}}}\right) \times P \ldots \ldots \ldots . . .17
\end{gathered}
$$

\subsection{Calculation of Gas Temperature}

The average gas film temperature $T_{f}$, is the mean of the temperature of the bulk gas and the temperature at the gasliquid interface. The film temperature was estimated using; ${ }^{16)}$

$$
T_{f}(K)=\frac{T_{g}+T_{b}}{2}
$$

In this study, the temperature of $\mathrm{CO}_{2}, T_{g}$ was assumed to equal to the temperature of impact zone whereas the temperature of $\mathrm{O}_{2}$ was assumed to be $25^{\circ} \mathrm{C}$. Koch et al. ${ }^{57,58)}$ suggested that the temperature at impact area increases very rapidly in the early blow and it stays at a maximum level during the active decarburization period. Towards the end of the blow, the impact area temperature disappears. According to these studies, the impact temperature was assumed to be $2000^{\circ} \mathrm{C}$ until 4 min after the start of the blow, followed by an increase to $2500^{\circ} \mathrm{C}$ till $14 \mathrm{~min}$ after the blow and decreasing to the bath temperature towards the end of the blow in this study.

All dimensionless groups, thereby mass transfer coefficients of $\mathrm{CO}_{2}$ and $\mathrm{O}_{2}$ were calculated at the film temperatures of the related gasses as per previous studies ${ }^{9,16)}$ whereas rate constants $k_{f}, k_{r}$ and adsorption coefficient, $K_{s}$ were calculated at the impact temperature of the process.

\subsection{Calculation of Impact Area}

It is known that an increase in impact area increases the reaction rates significantly. ${ }^{26,59)}$ Zughbi $^{26)}$ studied experimentally the effects of bath surface area on the kinetics of decarburization reaction of $\mathrm{Fe}-\mathrm{C}$ melts using crucible tech- 
nique at $1450^{\circ} \mathrm{C}$. They found that a decrease in the bath area lowers the reaction rates. They observed that the reaction also takes place outer of the penetration area. However, there is limited knowledge on the reaction area at the impact zone due to the difficulties in measurements and visualization at high temperatures.

In this study, the penetration area was assumed to be the reaction area for carbon removal reaction. The multi-head lance creates individual cavities on the liquid bath. The total impact area of a jet can be calculated by summation of individual areas for multi-head lance. $\left.{ }^{6}\right)$ The shape of the cavity was assumed to be paraboloid. ${ }^{49,59)}$ The individual impact area was calculated using;

$$
\begin{aligned}
\text { Area } & =\int 2 \pi r \sqrt{d r^{2}+d h^{2}} \\
& =2 \pi \int_{0}^{r} r \sqrt{1+\left(\frac{d h}{d r}\right)^{2} d r} \\
& =2 \pi \sum r_{i} \sqrt{1+\left(\frac{h_{i+1}-h_{i}}{r_{i+1}-r_{i}}\right)^{2}}\left(r_{i+1}-r_{i}\right)
\end{aligned}
$$

where $h$ is paraboloid height and $r$ is paraboloid radius. The height equals to the penetration depth which can be calculated using Korea and Lange's ${ }^{60)}$ relationship. Similarly, the radius equals to half of the penetration diameter and was also taken from Koria and Lange. ${ }^{50)}$ There would be also the change in the cavity throughout the blow due to the surface waves. But this effect was ignored based on the findings from a study of Cheslak et al. ${ }^{49)}$ since the cavity oscillations did not affect the final result of their observations.

\subsection{Calculation of Critical Carbon Content}

It might be hard to accept a constant value for the critical carbon content. However, it is well known that the value is below 1. Different proposals were made to determine the critical carbon content of liquid iron. Goldstein and Fruehan $^{61)}$ defined the critical carbon content as the carbon content where the decarburization reaction rate during the main blow equal to the decarburization rate at the end of the blow. In this study, this approach was used and it was assumed that the point where the total rate of decarburization via gases is equal to the decarburization rate controlled by mass transfer of carbon in the liquid iron represents the critical carbon content. This value was obtained using;

$$
C_{c r}=\frac{\frac{24 A}{\rho V} k_{g} \ln \left(1+P_{O_{2}}^{b}\right)+\frac{12 A}{\rho V} k_{a} P_{C O_{2}}^{b}}{k_{m} A \rho}
$$

\subsection{Calculation of Physical Properties of Gas}

\subsubsection{Viscosity}

The viscosity of gases can be estimated using the Lennard-Jones parameter. The relationship is given; ${ }^{62-65)}$

$$
\mu_{g}=266.93 \times 10^{-7} \frac{\sqrt{m w_{g} \times T_{f}}}{d_{c}^{2} \times \Omega_{\mu}}
$$

where molecular weight of gas is expressed as $m w g$ and collision diameter of gas is as $d_{c}$. The collision integral can be approximated by ${ }^{63}$ )
Table 1. Characteristic parameter of gases. ${ }^{66)}$

\begin{tabular}{lccc}
\hline Characteristic parameters & $\mathrm{O}_{2}$ & $\mathrm{CO}$ & $\mathrm{CO}_{2}$ \\
\hline$\varepsilon / k$ & 113.2 & 110.3 & 190 \\
$d_{c},\left(10^{-10} \mathrm{~m}\right)$ & 3.433 & 3.59 & 3.996 \\
\hline \multicolumn{1}{c}{$\Omega_{\mu}=1.147\left(\frac{k T}{\varepsilon}\right)^{-0.145}+\left(\frac{k T}{\varepsilon}+0.5\right)^{-2}$} & $\ldots \ldots \ldots . .$.
\end{tabular}

In this equation, a molecule's kinetic energy was represented by $k T$ while the potential energy of two colliding molecules was represented by $\varepsilon$, which was Lennard-Jones potential well depth. The characteristic parameters, $\varepsilon / k$ and $d_{c}$ for $\mathrm{O}_{2}, \mathrm{CO}$ and $\mathrm{CO}_{2}$ were taken from the literature ${ }^{66)}$ and are given in Table 1.

\subsubsection{Diffusivity}

The Chapman-Enskog theory was applied to predict the interdiffusivity of gases as a function of temperature. The relationship is; ${ }^{43,66)}$

$$
D_{A B}=\frac{0.0018583 T_{f}^{3 / 2}}{P \times d_{c, A B}^{2} \times \Omega_{D, A B}} \sqrt{\frac{1}{m w_{A}}+\frac{1}{m w_{B}}} \ldots \ldots . .
$$

where the collision diameter between gases can be found using; ${ }^{43,63)}$

$$
d_{c, A B}=0.5\left(d_{c, A}+d_{c, B}\right)
$$

The collision integral for mixtures can be approximated by Cloutman ${ }^{63)}$ using;

$$
\begin{aligned}
& \Omega_{D, A B}=\left(\frac{k T}{\varepsilon_{A B}}\right)^{-0.145}+\left(\frac{k T}{\varepsilon_{A B}}+0.5\right)^{-2} \\
& \left(\frac{\varepsilon_{A B}}{k}\right)=\left(\frac{\varepsilon_{A}}{k} \frac{\varepsilon_{B}}{k}\right)^{0.5}
\end{aligned}
$$

\subsection{Formulation of the Model}

The sequence of calculation procedure for decarburization in impact zone model is shown in Fig. 1. The data from hot metal composition such as carbon and sulphur, oxygen flow rate, lance height and bottom gas flow rate with time were taken from the related sub-models. The penetration area was calculated as a function of lance dynamics and gas flow rates.

The values from bath temperature sub-model were used to calculate the gas film temperatures since the physical properties of gasses, thereby dimensionless groups such as $R e, S c$ were calculated as a function of gas film temperature. Mass transfer rates of $\mathrm{CO}_{2}$ and $\mathrm{O}_{2}$ and the rate constant for $\mathrm{CO}_{2}$ reaction were estimated using Eqs. (7), (8), (9) and (11) to calculate individual decarburization rates via oxygen and carbon dioxide.

\subsection{Model Validation}

Model predictions for overall rate constants of $\mathrm{CO}_{2}$ including both gas diffusion and chemical kinetics are given as a function of sulphur concentration in Fig. 2. The predictions were compared with the experimental data of Sain and 


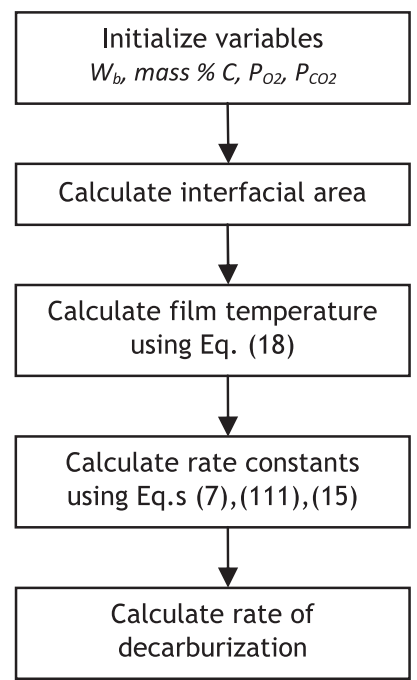

Fig. 1. Algorithm of the decarburization at impact zone model.

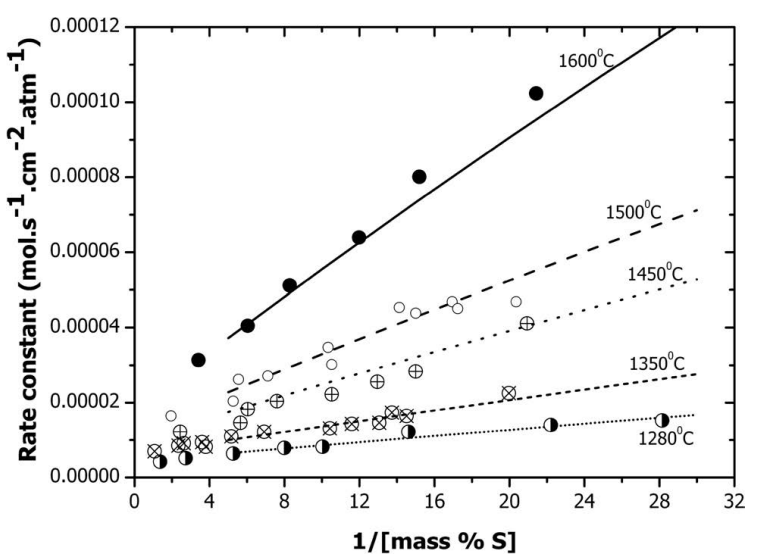

Fig. 2. Rate constant of $\mathrm{CO}_{2}$ as a function of sulphur concentration calculated at different temperatures using the data of Sain and Belton ${ }^{7,30)}$ Closed circles are for experimental data, solid lines are for model results.

Belton. ${ }^{7,30)}$ Experiments were carried out with a lance height of $2-3 \mathrm{~mm}$ and a flow rate of $0.02-0.03 \mathrm{~m}^{3} / \mathrm{min} . \mathrm{CO}_{2}$ gas was blown with $\mathrm{Ar}$ and $\mathrm{N}_{2}$ gases onto the liquid iron bath between 1160 and $1600^{\circ} \mathrm{C}$. The solid lines represent the model predictions whereas the points were related to the experimental data by Sain and Belton.

The model results are consistent with the experimental data reported by the previous researchers. The mass transfer coefficient values are much higher (approximately $6 \times 10^{-4}$ $\mathrm{mol} / \mathrm{m}^{2}$.Pa.s for $0.2-0.1$ mass $\%$ sulphur and $10 \mathrm{l} / \mathrm{min}$ gas flow rate at $1600^{\circ} \mathrm{C}$ ) than the chemical kinetics constants $\left(3.7-5.5 \times 10^{-5} \mathrm{~mol} / \mathrm{m}^{2}\right.$.Pa.s) that the decarburization reaction is controlled by the dissociative adsorption of $\mathrm{CO}_{2}$. Accordingly, the reaction rate is influenced by the temperature of the bath and sulphur concentration of liquid iron. As the temperature of the bath increases, the rate increases.

\section{Results and Discussion}

\subsection{Rate Constants}

The model was further studied using the industrial conditions reported by Cicutti et al., ${ }^{67)}$ i.e. top-blown oxygen with a flow rate of $620 \mathrm{Nm}^{3} / \mathrm{min}$ onto the 200 ton oxygen steel-

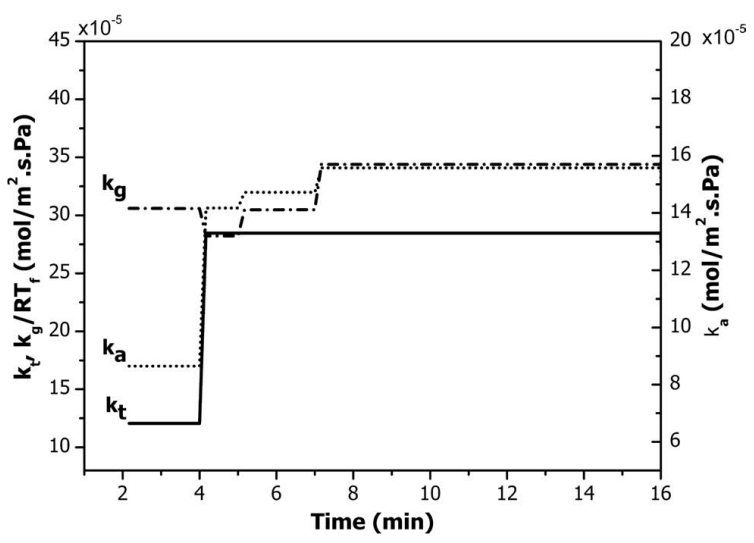

Fig. 3. The variations in rate constants for $\mathrm{CO}_{2}$ throughout the blow.

making vessel. The inert gas was ejected through the bottom of the furnace to increase the mixing properties of the liquid bath. The lance design and some other process conditions were provided in Part 1 of this series of papers. The bath sulphur concentration was assumed to be constant with a value of 0.015 mass $\%$ during the blow. Figure 2 shows the predictions for the rate constants for $\mathrm{CO}_{2}$ during the blow. The mass transfer coefficient, $k_{g}$ was influenced by gas velocity, penetration profile and physical properties of the gasses, simultaneously and the values of $k_{g} / R T_{f}$ varied between 25 $35 \times 10^{-5} \mathrm{~mol} / \mathrm{m}^{2} . \mathrm{s} . P a(270-378 \mathrm{~m} / \mathrm{min})$. The predicted values for the mass transfer coefficient of oxygen in the gas phase were between 560 and $670 \mathrm{~m} / \mathrm{min}$. An increase in gas velocity and impact area radius causes an increase in the gas-metal transfer coefficients. In practice, these properties vary dynamically and have an important impact on the overall kinetics of the system.

The reaction rate constant, $k_{t}$ is only a function of impact temperature since sulphur concentration is assumed to remain constant during the blow. Consequently, as the impact zone temperature decreases, the reaction rate constant also decreases. As can be seen in Fig. 3, the values for gas diffusion and chemical reaction constants are close to each other 2 min after the start of blowing. This suggests that the decarburization of liquid iron via $\mathrm{CO}_{2}$ at the impact zone is influenced by both mixed controlled at high carbon concentration under the various operating conditions such as temperature, gas flow rate and lance height.

\subsection{Impact Area}

The impact area was calculated as a function of penetration depth and diameter. Figure 4 shows the predicted individual impact area as a function of lance dynamics. As the lance height decreases, the penetration depth increases and the radius of the penetration decreases. At lower lance heights, the penetration would be deeper with lower penetration radius therefore, penetration area would decrease. These findings are in agreement with those by Koria and Lange. ${ }^{50)}$ The individual penetration area ranges between 2.6 and $2.3 \mathrm{~m}^{2}$ using Eq. (21). In this study, it is assumed that the interaction between the separate jets does not occur. This assumption is valid for jets with an inclination angle higher than $8^{\circ}$. Consequently, the total impact area is predicted to vary from 13 to $15.5 \mathrm{~m}^{2}$. 


\subsection{Decarburization via $\mathrm{O}_{2}$}

The reaction rates of decarburization via oxygen were calculated using Eq. (5) as a function of partial pressure of oxygen, impact area and mass transfer of oxygen in the gas boundary layer given in Fig. 5. The reaction rates varied from 180 to $220 \mathrm{~kg} / \mathrm{min}$. The reaction rate increases the impact area or mass transfer constant or partial pressure of oxygen increases. The reaction rates increases throughout the blow except the periods when the partial pressure of oxygen drops significantly. It was found that, if the partial pressure decreases from 26.4 to $16.2 \mathrm{kPa}$, the decarburization rate decreased from 202 to $134 \mathrm{~kg} / \mathrm{min}$. This suggests that partial pressure of oxygen has a decisive impact on the decarburization rates. However, it should be noted that these parameters have relative importance on the kinetics of decarburization reactions via oxygen gaseous in a dynamic oxygen steelmaking process.

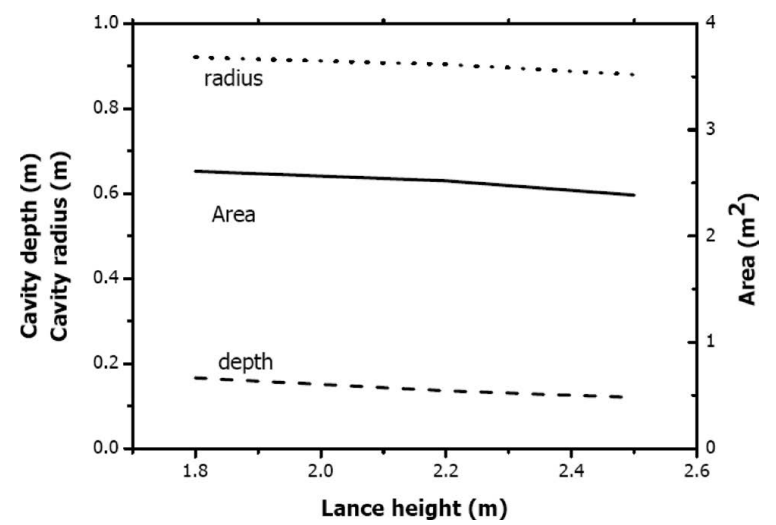

Fig. 4. The changes in impact area as a function of penetration depth, radius and lance height.
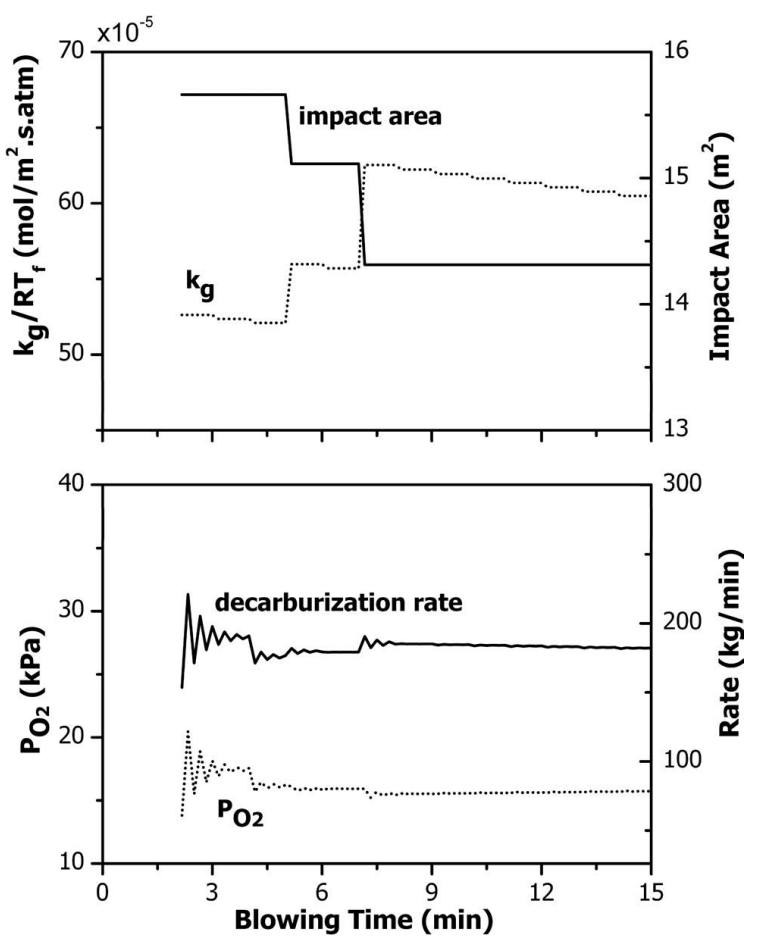

Fig. 5. Decarburization reaction via oxygen as a function of partial pressure of oxygen, impact area and mass transfer coefficient.

\subsection{Decarburization via $\mathrm{CO}_{2}$}

Figure 6 gives the estimated decarburization rates via $\mathrm{CO}_{2}$ as a function of partial pressure of $\mathrm{CO}_{2}$, apparent rate constant and impact area for the region above the critical carbon content. The rates of decarburization were calculated for $\mathrm{CO}_{2}$ using Eq. (3). The reaction rate dropped much less rapidly with the partial pressure of $\mathrm{CO}_{2}$ with compared to rates of decarburization via oxygen. For example, the increase in partial pressure of $\mathrm{CO}_{2}$ increases the reaction rate slightly with time in the early part of the blow as the impact area and rate constant remain constant.

A similar pattern emerges in the comparison of the estimated rate constant and decarburization rate in Fig. 6. This implies that apparent rate constant is relatively more important on the kinetics of the decarburization reaction via $\mathrm{CO}_{2}$.

\subsection{Effect of Bottom Stirring}

In industrial practice, inert gas was blown through the bottom of the furnace at a flow rate of $150 \mathrm{Nm}^{3} / \mathrm{h}$. This flow rate was increased to $500 \mathrm{Nm}^{3} / \mathrm{h}$ in the last two min of the process. Below critical carbon content, metal-phase mass transfer controlled the refining rates. It is known that bottom stirring increases the transfer rates in the bath significantly. ${ }^{68,69)}$

Figure 7 shows the predictions of decarburization rate as a function of gas flow rate, carbon concentration and mass transfer coefficient of carbon in liquid iron. As can be seen,

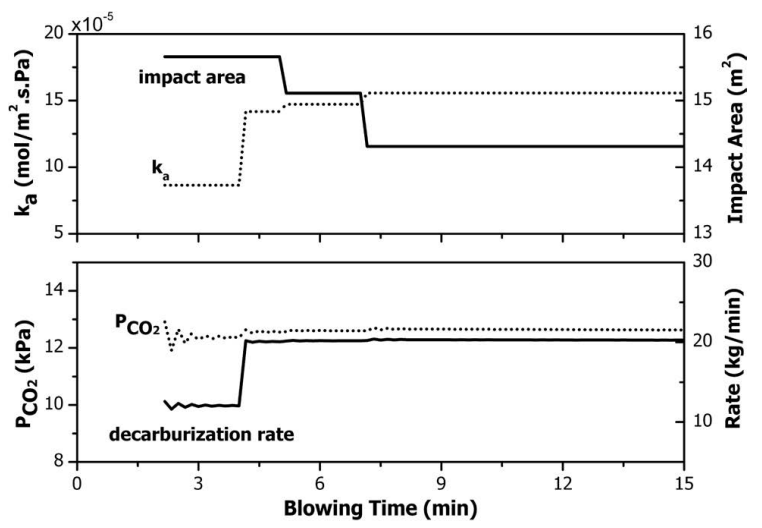

Fig. 6. Decarburization reaction via carbon dioxide as a function of partial pressure of oxygen, impact area and mass transfer coefficient.

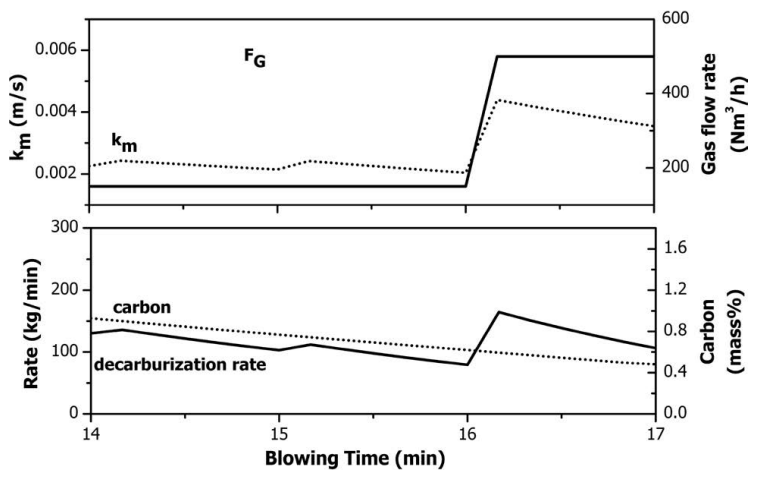

Fig. 7. Evolution of reaction rate as a function of mass transfer coefficient, carbon content of liquid iron and inert gas flow rate predicted by the proposed model. 
decarburization rate is dependent on carbon concentration and decreases as the carbon content decreases towards the end of the blow. However, it is also shown that as the bottom gas flow rate is increased to $500 \mathrm{Nm}^{3} / \mathrm{h}$, the value of mass transfer coefficient and decarburization rate increase.

\subsection{Decarburization Rate in Impact Zone}

In the study by Cicutti et al., ${ }^{67)}$ the instantaneous decarburization rates were not provided and the overall reaction rates were calculated based on the predictions on the carbon content of liquid iron. The direct comparison of reaction rates in the impact zone is difficult. In this study, the decarburization rate in the impact zone was estimated by subtraction of calculated decarburization rates in emulsion phase from the overall decarburization rates estimated from the study of Cicutti et al. ${ }^{67)}$ In the model, total decarburization rate in the impact zone was obtained by the summation of two different decarburization rates via $\mathrm{O}_{2}$ and $\mathrm{CO}_{2}$ above the critical carbon content.

Figure 8 compares the decarburization rate via $\mathrm{O}_{2}$ and $\mathrm{CO}_{2}$ in the impact zone during the blow predicted by the model and estimated from the study of Cicutti et al. ${ }^{67)}$ As seen from the figure, the reaction rate of carbon was divided into two distinct regions according to the critical carbon content of the liquid bath. The critical carbon content was obtained using Eq. (22). However, the values obtained from the numerical calculations were higher than the real case. (above 1 mass\%) This is most likely due to the low mass transfer coefficients. In this calculation, an empirical relationship was used to calculate the mass transfer coefficient. Further study is required for better understanding of mixing in the liquid bath under the industrial conditions. Therefore, the authors used a fixed value of 0.5 for the values of critical carbon content for simplicity. In region 1 (above the critical carbon content), the rate of carbon oxidation is independent of carbon concentration but subjected to the fluid flow and partial pressure of gasses. The decarburization reaction via oxygen is controlled by gas diffusion and has the major role on the overall kinetics of the reaction at the impact zone. In the case of $\mathrm{CO}_{2}$, both chemical reaction and gas diffusion limit the reaction kinetics.

In region 2 , the decarburization rate decreases rapidly

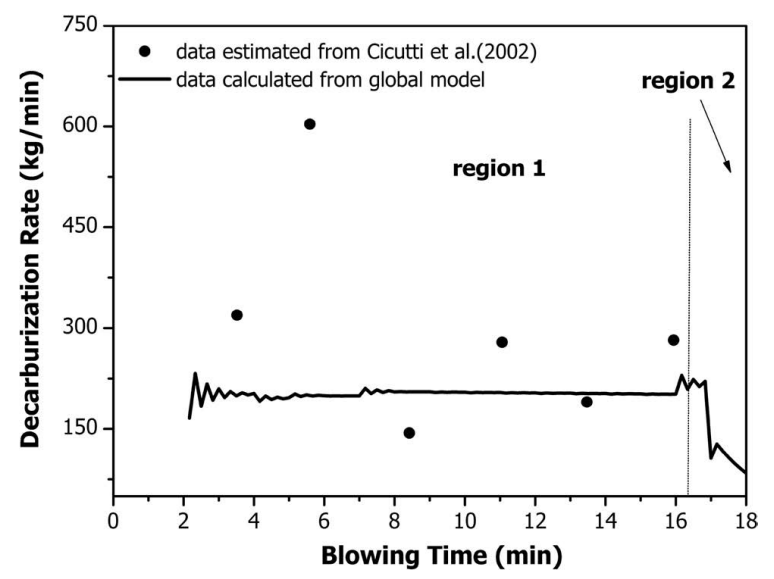

Fig. 8. The comparison of decarburization rate at the impact zone predicted by the model and estimated from the study by Cicutti et al. below the critical carbon content of the liquid iron (mass\% $\mathrm{C}<1$ ). The reaction rate is assumed to be controlled by the carbon diffusion in the liquid metal using Eq. (6). The reaction rate is strong function of mass transfer coefficient and carbon concentration of liquid bath. As the carbon concentration decreases, the reaction rate decreases simultaneously.

The estimated decarburization rates from the study of Cicutti et al. were represented by the points and the model results were represented by the line in Fig. 8. Some differences were observed in the figure. Nevertheless, as discussed in Part 1 of this series of papers, the evolution of carbon content of liquid iron is in good agreement with the industrial data. This means that combining the two models provides a reasonable estimate of the overall decarburization rate and therefore the model for the impact zone provides a reasonable basis for predicting the decarburization rate in the impact region.

\section{Conclusion}

A kinetic model involving decarburization reactions with $\mathrm{O}_{2}$ and $\mathrm{CO}_{2}$ that provides a quantitative understanding on how different operational parameters affect the decarburization rates at the impact zone under full-scale operating conditions has been developed. The model simulations were applied to given top and bottom gas flow rates on full scale operating conditions. The results from the model indicate the followings:

- In region 1 (above critical $\mathrm{C}$ content), higher decarburization rates were predicted when $\mathrm{O}_{2}$ was used as oxidizing gas instead of $\mathrm{CO}_{2}$. Partial pressure of oxygen has a marked affect on the decarburization kinetics via $\mathrm{O}_{2}$.

- The predicted rate constants showed that sulphur has a retarding effect on the decarburization reaction via $\mathrm{CO}_{2}$.

- In region 2 (below critical $\mathrm{C}$ content), decarburization rates decreased as the carbon content is decreased towards the end of the blow. The increase in bottom stirring from 150 to $500 \mathrm{Nm}^{3} / \mathrm{min}$ increases the transfer rates significantly.

The impact zone model was validated against the estimated values derived from the study of Cicutti et al. since it is very difficult to measure the decarburization rates at the impact zone individually and distinguish the gas production $\left(\mathrm{CO}\right.$ and $\left.\mathrm{CO}_{2}\right)$ from the off-gas analysis. Based on the model predictions, it can be approximated that $40 \%$ of decarburization takes place in the impact zone during the main blow. Limited data exist for real systems, and further investigations are needed to refine these correlations and further establish their integrity and validity.

\section{REFERENCES}

1) F. J. Mannion and R. J. Fruehan: Metall. Trans. B, 20 (1989), 853.

2) S. Okano, J. Matsuno, H. Ooi, K. Tsuruoka, T. Koshikawa and A. Okazaki: Int. Conf. on Science and Technology of Iron and Steel, ISIJ, Tokyo, (1971), 227.

3) K. Ito, K. Amano and H. Sakao: Trans. Iron Steel Inst. Jpn., 24 (1984), 515.

4) N. Dogan, G. A. Brooks and M. A. Rhamdhani: ISIJ Int., 51 (2011), 1093

5) N. Dogan, G. A. Brooks and M. A. Rhamdhani: ISIJ Int., 51 (2011), 1086.

6) B. Deo and R. Boom: Fundamentals of Steelmaking Metallurgy, Prentice Hall Int., New York, (1993), 21. 
7) D. R. Sain and G. R. Belton: Metall. Mater. Trans. B, 7 (1976), 235.

8) H. G. Lee and Y. K. Rao: Metall. Mater. Trans. B, 13 (1982), 403.

9) H. G. Lee and Y. K. Rao: Metall. Mater. Trans. B, 13 (1982), 411

10) H. G. Lee and Y. K. Rao: Iranmaking Steelmaking, 15 (1988), 238.

11) Y. K. Rao and H. G. Lee: Ironmaking Steelmaking, 15 (1988), 228.

12) D. G. C. Robertson and A. E. Jenkins: Heterogeneous Kinetics at Elevated Temperatures, Plenum Press, New York, (1970), 393.

13) L. A. Baker and R. G. Ward: J. Iron Steel Inst., 205 (1967), 714.

14) L. A. Baker, N. A. Warner and A. E. Jenkins: Trans. Metall. Soc. AIME, 239 (1967), 857.

15) J. H. Swisher and E. T. Turkdogan: Trans. Metall. Soc. AIME, 239 (1967), 602.

16) P. A. Distin, G. D. Hallett and F. D. Richardson: J. Iron Steel Inst., 206 (1968), 821.

17) H. Nomura and K. Mori: Trans. Iron Steel Inst. Jpn., 13 (1973), 325.

18) H. Nomura and K. Mori: Trans. Iron Steel Inst. Jpn., 13 (1973), 265.

19) P. G. Roddis: J. Iron Steel Inst., 211 (1973), 53.

20) R. J. Fruehan and L. J. Martonik: Metall. Mater. Trans. B, 5 (1974), 1027.

21) L. A. Greenberg and A. McLean: Trans. Iron Steel Inst. Jpn., 14 (1974), 395.

22) T. Nagasaka and R. J. Fruehan: Metall. Mater. Trans. B, 25 (1994), 245.

23) H. Sun and R. D. Pehlke: Metall. Mater. Trans. B, 26 (1995), 335.

24) H. Sun and R. D. Pehlke: Metall. Mater. Trans. B, 27 (1996), 854.

25) H. D. Zughbi: Scand. J. Metall., 32 (2003), 194.

26) H. D. Zughbi: Scand. J. Metall., 33 (2004), 242.

27) H. Sun and R. D. Pehlke: Trans. Am. Foundary's Soc., 100 (1992), 371.

28) K. Koch, J. Falkus and R. Bruckhaus: Steel Res., 64 (1992), 15.

29) A. I. Kondrat'ev, N. V. Gavrikov, B. S. Ivanov, A. F. Kablukovskii and V. V. Kazanskii: Steel USSR, 8 (1978), 439.

30) D. R. Sain and G. R. Belton: Metall. Mater. Trans. B, 9 (1978), 403.

$31)$ R. J. Fruehan and S. Antolin: Metall. Trans. B, 18 (1987), 415.

32) H. Sun, K. Gao, V. Sahajwalla, K. Mori and R. D. Pehlke: ISIJ Int., 39 (1999), 1125.

33) M. Hayer and S. Whiteway: Can. Metall. O., 12 (1973), 35.

34) K. Goto, M. Kawakami and M. Someno: Trans. Metall. Soc. AIME, 245 (1969), 293.

35) D. Widlund, D. S. Sarma and P. G. Jonsson: ISIJ Int., 46 (2006), 1149 .

36) C. Blanco and M. Diaz: ISIJ Int., 33 (1993), 757.

37) E. T. Turkdogan and R. Fruehan: Fundamentals of Iron and Steelmaking Steelmaking and Refining Volume, R. J. Fruehan, The AISE Steel Foundation, Pittsburgh, (1998), 64.

38) V. V. Rao and O. Trass: Can. J. Chem. Eng., 42 (1964), 95.

39) M. T. Scholtz and T. Olev: AIChE J., 9 (1963), 548.

40) G. C. Huang: J. Heat Transfer, 85 (1963), 237.

41) H. Lohe: Warme- und Stofftransport beim Aufblasen von Gasstrahlen auf Flussigkeiten. Fortschrittsber, VDI-Z. Reihe 3, Düsseldorf,
(1967) No. 15.

42) G. R. Belton and R. A. Belton: Trans. Iron Steel Inst. Jpn., 20 (1980), 87.

43) G. H. Geiger and D. R. Poirier: Transport Phenomena in Material Processing, TMS, Warrandale, PA, (1994), 298.

44) R. Li and R. L. Harris: Pyrometallurgy'95 Conf. Proc., IMM, London, (1995), 107.

45) Subagyo, G. A. Brooks, K. S. Coley and G. A. Irons: ISIJ Int., 43 (2003), 983.

46) R. B. Banks and D. V. Chandrasekhara: J. Fluid Mech., 15 (1963), 13.

47) E. T. Turkdogan: Chem. Eng. Sci., 21 (1966), 1133.

48) R. S. Rosler and G. H. Stewart: J. Fluid Mech., 31 (1968), 163.

49) F. R. Cheslak, J. A. Nicholls and M. Sichel: J. Fluid Mech., 36 (1969), 55.

50) S. C. Koria and K. W. Lange: Steel Res., 58 (1987), 421.

51) T. Nagasaka and R. J. Fruehan: ISIJ Int., 34 (1994), 241.

52) S.-H. Kim and R. Fruehan: Metall. Mater. Trans. B, 18 (1987), 381.

53) S. Paul and D. Ghosh: Metall. Mater. Trans. B, 17 (1986), 461.

54) M. Hirasawa, K. Mori, M. Sano, A. Hatanaka, Y. Shimatani and Y. Okazaki: Trans. Iron Steel Inst. Jpn., 27 (1987), 277.

55) M. Martin, M. Renduelles and M. Diaz: Chem. Eng. Res. Design, 83 (2005), 1076.

56) F. Oeters: Metallurgy of Steelmaking, Verlag Stahl Eisen $\mathrm{mbH}$, Düsseldorf, (1994), 37.

57) K. Koch, W. Fix and P. Valentin: Arch. Eisenhüttenwes, 47 (1976), 659.

58) K. Koch, W. Fix and P. Valentin: Arch. Eisenhüttenwes, 49 (1978), 231.

59) R. Imai, K. Kawakami, S. Miyoshi and S. Jinbo: Nippon Kokan Tech. Rep. (1967), 19.

60) S. C. Koria and K. W. Lange: Ironmaking Steelmaking, 10 (1983), 160

61) D. Goldstein and R. Fruehan: Metall. Mater. Trans. B, 30(1999), 945.

62) J. O. Hirschfelder, C. F. Curtiss and R. B. Bird: Molecular Theory of Gases and Liquids, Wiley \& Sons, New York, (1954), 529.

63) L. D. Cloutman: A Database of Selected Transport Coefficients for Combustion Studies, Livermore, California, (1993), 15.

64) R. I. L. Guthrie: Engineering in Process Metallurgy, Oxford University Press Inc., New York, (1989), 474.

65) J. Hilsenrath and Y. S. Toulokian: Trans. ASME, 76 (1954), 967.

66) J. O. Hirschfelder, R. B. Bird and E. L. Spotz: J. Chem. Phys., 16 (1948), 968

67) C. Cicutti, M. Valdez, T. Perez, J. Petroni, A. Gomez, R. Donayo and L. Ferro: 6th Int. Conf. on Molten Slags Flux. Salts, ISS, Warrendale, PA, (2000), 367.

68) J. Nagai, H. Take, K. Nakanishi, T. Yamamota, R. Tachibana, Y. Iida, H. Yamada and H. Omori: Kawasaki Steel Giho, (1982), 12.

69) M. Martin, C. Blanco, M. Rendueles and M. Diaz: Ind. Eng. Chem. Res., 42 (2003), 911. 